\title{
CompanHIA dOS Materials Atividade Envolvendo os Pais na Aprendizagem da Química
}

\author{
Carla Morais $^{1}$, João Paiva ${ }^{2}$
}

\begin{abstract}
$A$ A presentam-se alguns argumentos para a participação dos pais/familiares, na aprendizagem da Química e para um maior envolvimento destes nas tarefas escola-casa e, na sequência, apresenta-se uma atividade "Pais na Aprendizagem da Química" (PAQ). Tal atividade poderá contribuir para promover um envolvimento mais ativo dos alunos na Química, relembrando os principais conceitos que foram abordados em aulas prévias à realização da atividade em casa com os pais/familiares. Para os pais/familiares, esta atividade poderá constituir-se como uma possibilidade de acompanharem o(a) seu(sua) educando(a), estimulando a coparticipação no processo de aprendizagem.
\end{abstract}

A conceção do aluno como um ser social e cultural, que se desenvolve na interação com outros, coloca a tónica no paradigma do desenvolvimento em contexto marcado, entre outros, pela influência da teoria sociocultural de Vygotsky [1]. Este autor deu particular ênfase ao estudo das funções ainda em desenvolvimento, ou seja, ao desenvolvimento potencial do aluno. À diferença entre o nível de desenvolvimento real e o nível de desenvolvimento potencial, Vygotsky deu o nome de Zona de Desenvolvimento Proximal (ZDP). Pode definir-se a ZDP como o espaço onde, graças à interação e à ajuda de outros, uma pessoa pode trabalhar e resolver um problema ou realizar uma tarefa de uma maneira e a um nível que não seria capaz de atingir se trabalhasse individualmente. A ZDP é uma zona onde, graças aos reforços e ajudas dos outros, é possível o processo de construção, modificação, enriquecimento e diversificação dos esquemas de conhecimento, característicos da aprendizagem escolar [2]. Tal como tentamos mostrar, de forma breve, este paradigma carece de um modelo de ensino que vai além da escola. Exige envolver os pais, a família e a comunidade, dar aplicabilidade aos conteúdos, contextualizando-os e mobilizando-os em diferentes situações, permitindo a sua apropriação de uma forma individualizada e autorregulada [3].

Departamento de Química e Bioquímica da Faculdade de Ciências da Universidade do Porto

E-mail: carlamorais@emultimedia.com.pt

Departamento de Química e Bioquímica da Faculdade de Ciências da Universidade do Porto

E-mail: jcpaiva@fc.up.pt
São estes os principais pressupostos que fundamentam a utilização das atividades conhecidas pelo acrónimo TIPS (Teachers Involving Parents in Schoolwork), nomeadamente na aprendizagem da Química. O principal objetivo destas atividades consiste no desenvolvimento de parcerias, levando o aluno a partilhar em casa o que aprendeu em contexto escolar. Desta forma as TIPS são alavancadoras de duas importantes redefinições na medida em que os "trabalhos de casa" passam a significar, não apenas o trabalho que o aluno faz sozinho, mas também as atividades partilhadas com os pais/familiares ou outros elementos da comunidade; por outro lado, a própria ideia de "ajuda em casa" ou "ajuda dos pais" poderá significar encorajar, ouvir, responder, premiar, guiar, supervisionar e discutir sem a pretensão de "ensinar" os conteúdos escolares [3, 4].

Para as TIPS especificamente destinadas à aprendizagem da Química tem-se usado o acrónimo PAQ - Pais na Aprendizagem da Química [3]. Assim, seguindo esta terminologia, e na senda de outros artigos já publicados no boletim da SPQ $[5,6]$, apresenta-se uma PAQ sobre a variedade e as propriedades dos materiais que nos rodeiam, com tarefas de caris prático, recorrendo a material não sofisticado e de tipo "caseiro". A temática subjacente à $P A Q$ é lecionada na disciplina de Ciências Físico-Químicas no $7^{\circ}$ ano de escolaridade do $3^{\circ}$ ciclo do Ensino Básico.

Apraz-nos evidenciar que se pretende progressivamente evitar o caráter "receituário" das atividades prático-laboratoriais em Química. Contudo, não é de abandonar radicalmente o caráter prescritivo de algumas iniciativas, pelo que se considera que uma certa orientação nas PAQ - com a referência clara ao tema em estudo, material a utilizar, procedimentos essenciais, ícones para auxiliar na estruturação dos desafios propostos, espaço no qual possam ser registadas as opiniões e os resultados ao longo da realização de toda a atividade - pode conferir segurança aos intervenientes (pais/familiares e alunos) e, pelo menos numa primeira fase, tornar estas iniciativas mais populares, funcionais e democráticas.

Embora a par disto seja crucial estimular também espaços para a discussão dos resultados obtidos - que se podem constituir como um fator promotor de um maior envolvimento de toda a família na atividade - de autoconstrução e delineamento de dinâmicas com maior grau de flexibilidade.

É fundamental que ao longo de toda a PAQ seja utilizada uma linguagem acessível e que os desafios propostos tenham por base o "não elitismo", prestando-se a ser abordados por pais/famílias de qualquer nível sociocultural.

Espera-se que a utilização mais generalizada das $P A Q$ possa, de alguma forma, constituir-se como uma alavanca para uma aprendizagem da Química mais participada, fascinante e significativa. 


\section{REFERÊNCIAS}

[1] Vygotsky, L. S. (1978). Mind in society: The development of higher psychological processes. Cambridge: Harvard University Press.

[2] Coll, C., Martin, E., Mauri, T., Miras, M., Omrubia, J., Solé, I., \& Zabala, A. (2001). O construtivismo na sala de aula. Porto: Edições ASA.
[3] Paiva, J., Gaspar, M. (2005). Actividades participadas pelos pais na aprendizagem da Química (PAQ). Boletim da Sociedade Portuguesa de Química, 97, 73-79.

[4] Epstein, J., Sanders. M., Simon S., Salinas, K., Jansorn, N. \& Voorhis, F. (2002). School, family, and community partnerships: Your handbook for action, Second Edition. Thousand Oaks:
Corwin Press.

[5] Meireles, M., Paiva, J. (2005). Redox em casa. Boletim da Sociedade Portuguesa de Química, 97, 81-82.

[6] Póvoa, A., Sottomayor M. J., Paiva, J. (2006). Métodos físicos de separação 'domésticos': Uma actividade envolvendo os pais na aprendizagem da química (PAQ). Boletim da Sociedade Portuguesa de Química, 101, 58-59.

Dear Colleagues and Friends,

On behalf of the IUPAC Symposium Scientific Organizing Committee (SOC). I am very pleased to be able to invite you to attend the XXIV th IUPAC Symposium on Photochemistry, which will be held in Coimbra, from 15-20 July 2012.

Hugh D. Burrows (Portugal)

Chairman International Scientific Committee

\section{SYMPOSIUM KEY DATES}

\begin{tabular}{|l|l|}
\hline Registration Online Opens & 1 December 2011 \\
\hline Early Bird Registration Deadline & $\mathbf{6}$ May 2012 \\
\hline
\end{tabular}

\begin{tabular}{|l|l|}
\hline Abstract Submission Online Opens & 1 December 2011 \\
\hline Abstract Submission Deadline & 16 April 2012 \\
\hline Abstract Acceptance Notification & 30 April 2012 \\
\hline Registration Online Closes & 10 July 2012 \\
\hline Symposium Opening & 15 July 2012 \\
\hline
\end{tabular}

PROGRAMME TOPICS

- Organic and inorganic photochemistry from a synthetic and mechanistic point of view

- Solar energy conversion

- Photocatalysis, environmental and green photochemistry

- Materials science and engineering

- Supramolecular chemistry

- Photoactive nanoparticloes and nanomaterials

- Photobiology, biophysics and skin photochemistry

- Photochemistry in medicine

- Luminescent probes, sensors and imaging

- Spectroscopy and instrumentation

- Photochromism and photoswitching

- Industrial applications of photochemistry and photophysics

- Photochemistry and cultural heritage
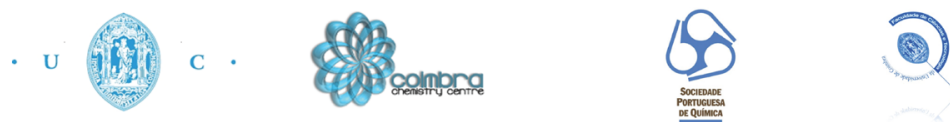

C Caixa Geral 5 de Depusitos

For General Information/ Symposium Secretariat: photoiupac2012secretariat@leading.pt

\section{www. photoiupac2012.com}




\title{
Companhia dos materiais Atividade Envolvendo os Pais na Aprendizagem da Química
}

\author{
Carla Morais, João Paiva
}

Departamento de Química e Bioquímica Centro de Investigação em Química da Universidade do Porto Faculdade de Ciências da Universidade do Porto, Portugal

\section{Caros pais/familiares:}

Nas aulas de Ciências Físico-Químicas temos vindo a estudar a classificação dos materiais e os tipos de misturas. Nesta atividade, composta por vários desafios, procuraremos conhecer melhor e classificar alguns dos materiais que nos rodeiam e que são indispensáveis no nosso dia-a-dia. É muito importante que, juntamente com o(a) aluno(a), façam todos os registos numa folha de papel que deve ser anexada a este documento.

Espero que gostem desta atividade!

Obrigado(a).

\section{Ícones usados na estruturação dos desafios propostos e respetivo significado:}

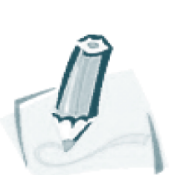

Registos

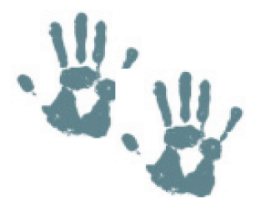

Dinâmicas práticas

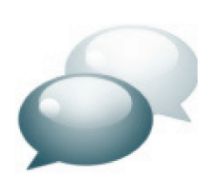

Debate

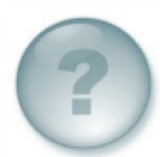

Questão

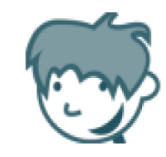

Intervenção do(a) aluno(a)

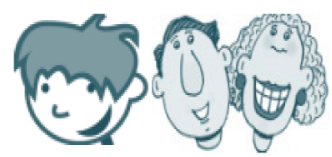

Intervenção do(a) aluno(a) e dos pais/familiares

\section{Vamos aos desafios. Bom trabalho!}




\begin{tabular}{|c|c|c|}
\hline Desafio & Interveniente (s) & Descrição do desafio \\
\hline 1 & & $\begin{array}{l}\text { - Inicia esta atividade começando por recordar como se classificam os } \\
\text { materiais atendendo à sua composição. } \\
\text { - Por palavras tuas, faz um pequeno registo escrito sobre esse tema } \\
\text { numa folha de papel. }\end{array}$ \\
\hline 2 & \multirow{4}{*}{ mescoseces } & $\begin{array}{l}\text { - Com a ajuda dos teus pais/familiares procura recolher os seguintes } \\
\text { conjuntos de materiais: }\end{array}$ \\
\hline & & 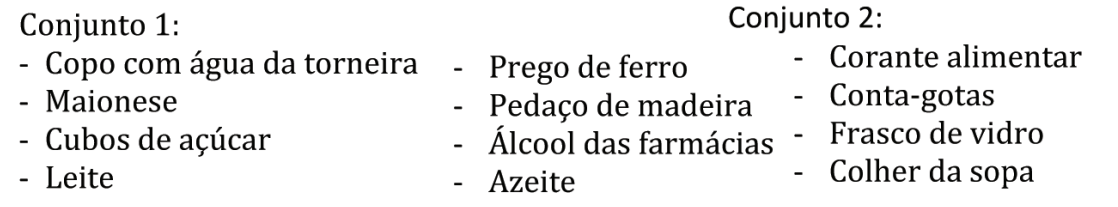 \\
\hline & & $\begin{array}{l}\text { - Conversa com os teus pais/familiares procurando explicar-lhes a } \\
\text { diferença entre substâncias e misturas de substâncias. } \\
\text { - Tenta certificar-te de que eles entenderam bem a tua explicação. }\end{array}$ \\
\hline 4 & & $\begin{array}{l}\text { - Realiza com os teus pais/familiares um exercício de aplicação, clas- } \\
\text { sificando os materiais presentes no conjunto } 1 \text { em substâncias ou } \\
\text { misturas de substâncias. } \\
\text { - Regista essa classificação na folha de papel a anexar a esta atividade. }\end{array}$ \\
\hline 5 & & $\begin{array}{l}\text { - Recorda como se classificam as misturas quanto à natureza de distri- } \\
\text { buição das substâncias que as constituem. } \\
\text { - Faz um pequeno registo escrito sobre isso, usando palavras tuas. }\end{array}$ \\
\hline & & $\begin{array}{l}\text { - Com a ajuda dos teus pais/familiares prepara uma mistura hetero- } \\
\text { génea líquido-líquido, recorrendo à água da torneira e a outro mate- } \\
\text { rial disponível no conjunto } 1 \text {. } \\
\text { - Juntamente com os teus pais/familiares observa a mistura obtida. }\end{array}$ \\
\hline 7 & & $\begin{array}{l}\text { - Como pode ser classificada esta mistura quanto à natureza de distri- } \\
\text { buição das substâncias que a constituem? } \\
\text { A - Mistura homogénea } \\
\text { B - Mistura heterogénea } \\
\text { C - Mistura coloidal } \\
\text { - Regista na folha de respostas a resposta correta. }\end{array}$ \\
\hline IIf & & $\begin{array}{l}\text { - Solicita aos teus pais/familiares que adicionem, cuidadosamente } \\
\text { com a ajuda de um conta-gotas, algumas gotas de corante à mistura } \\
\text { anterior. } \\
\text { - Juntamente com os teus pais/familiares observa o que aconteceu. }\end{array}$ \\
\hline 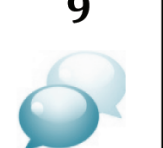 & & $\begin{array}{l}\text { - Debate com os teus pais/familiares por que é que se formam } \\
\text { pequenas bolinhas junto do azeite. } \\
\text { - Regista a tua opinião e a opinião dos teus pais/familiares. }\end{array}$ \\
\hline
\end{tabular}




\begin{tabular}{|c|c|c|c|c|}
\hline Desafio & Interveniente (s) & \multicolumn{3}{|c|}{ Descrição do desafio } \\
\hline 10 & & \multicolumn{3}{|c|}{$\begin{array}{l}\text { - Usando o cabo de uma colher da sopa solicita aos teus } \\
\text { pais/familiares que empurrem as bolinhas de corante até à água. } \\
\text { - Juntamente com os teus pais/familiares observa o que aconteceu. }\end{array}$} \\
\hline 11 & & \multicolumn{3}{|c|}{$\begin{array}{l}\text { Debate com os teus pais/familiares e procurem explicar o que acon- } \\
\text { tece às bolinhas logo que elas atingem a água. }\end{array}$} \\
\hline 12 & & \multicolumn{3}{|c|}{$\begin{array}{l}\text { - Descreve como procederias para, com base nos materiais dispo- } \\
\text { níveis no conjunto 1, preparares: } \\
\text { a. Uma solução aquosa líquida com um soluto líquido. } \\
\text { b. Uma solução aquosa líquida com um soluto sólido. } \\
\text { - Por palavras tuas, faz um pequeno registo escrito sobre isso. }\end{array}$} \\
\hline 13 & & \multicolumn{3}{|c|}{$\begin{array}{l}\text { - Debate com os teus pais/familiares o que acontece se adicionarmos: } \\
\text { a. Mais açúcar a um copo de água açucarada. } \\
\text { b. Mais água a um copo de água açucarada. }\end{array}$} \\
\hline 14 & & \multicolumn{3}{|c|}{$\begin{array}{l}\text { - Prepara três soluções aquosas de água com corante alimentar que } \\
\text { deverão manifestar diferentes intensidades de cor. } \\
\text { - Com base nelas explica aos teus pais/familiares o conceito de } \\
\text { "concentração de uma solução". }\end{array}$} \\
\hline 15 & & \multicolumn{3}{|c|}{$\begin{array}{l}\text { Considera a seguinte figura, que } \\
\text { representa a observação duma } \\
\text { amostra de leite ao microscópio. } \\
\text { Como se classifica esta mistura } \\
\text { quanto à natureza de distri- } \\
\text { buição das substâncias que a } \\
\text { constituem? } \\
\text { A - Mistura homogénea } \\
\text { B - Mistura heterogénea } \\
\text { C - Mistura coloidal } \\
\text { - Regista na folha de respostas a resposta correta. }\end{array}$} \\
\hline 16 & & \multicolumn{3}{|c|}{$\begin{array}{l}\text { - Olha à tua volta e, com a ajuda dos pais/familiares, preenche a } \\
\text { seguinte tabela (construindo uma equivalente na tua folha de } \\
\text { registos), indicando outras misturas heterogéneas, homogéneas e } \\
\text { coloidais existentes em tua casa. }\end{array}$} \\
\hline & & Misturas heterogéneas & Misturas homogéneas & Misturas coloidais \\
\hline
\end{tabular}


Para pensar e debater um pouco mais com os pais/familiares:

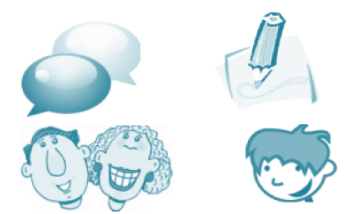

1. Quando um alimento se chama «puro», isso não quer dizer que seja uma substância única. Por exemplo, falar de «azeite puro» não significa que se trate de uma substância só.

a. Discute esta afirmação com os teus pais/familiares procurando explicitar as diferenças entre a linguagem científica e a linguagem do dia-a-dia.

b. Regista, na folha de respostas, as principais ideias resultantes deste debate.

2. Na Natureza, as substâncias raramente ocorrem no seu estado puro. Surgem normalmente como componentes de misturas.

a. Faz uma pesquisa em conjunto com os teus pais/familiares procurando misturas cujo processo de separação nas respetivas substâncias constituintes tenha particular importância no nosso dia-a-dia.

b. Regista, na folha de respostas, os principais resultados dessa pesquisa.

\section{Comunicação Casa-Escola:}

Caros pais/familiares: Expressem por favor a vossa opinião sobre o trabalho efetuado pelo(a) (nome do aluno), nesta atividade, assinalando a opção que melhor corresponder a cada caso:

- 0 (a) aluno (a) empenhou-se no trabalho e foi capaz de o fazer.
o Sim
○ Não

- O (a) aluno (a) e nós gostámos desta atividade e reconhecemos o seu valor pedagógico.
○ Sim
○ Não

- Esta atividade ajudou-nos a compreender o que o (a) aluno (a) está a aprender nas aulas da disciplina de Ciências Físico-Químicas.

○ Sim

○ Não

Outros comentários:

Assinatura dos pais/familiares:

Agradeço a sua colaboração.

$\mathrm{O}(\mathrm{A})$ professor(a) 